\title{
Extensive reading in a tertiary reading programme: Students' accounts of affective and cognitive benefits
}

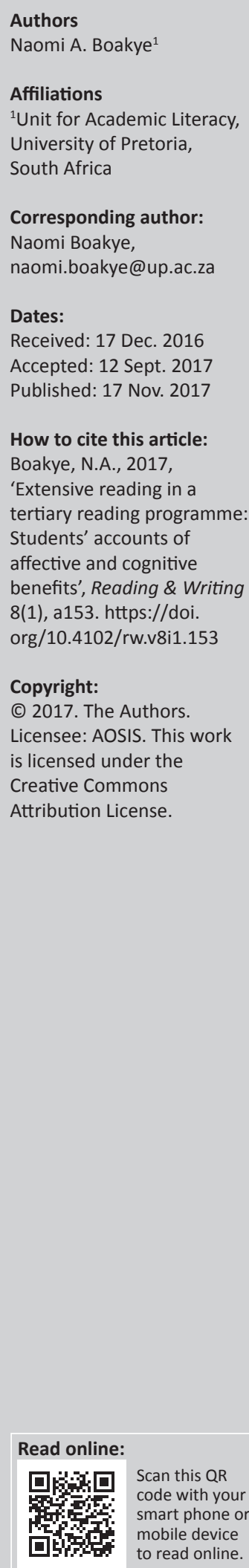

This article reports on the extensive reading (ER) component of a reading intervention programme to improve first-year students' reading proficiency. To make the intervention more practical and to accelerate improvement, an ER component was included in the programme. Two groups of first-year students (high-risk and low-risk) were required to read short stories and novels of their choice and to record their affective and cognitive experiences during the reading to submit as a portfolio. In addition, students answered pre- and post-intervention questionnaires on their reading habits. Students were selected based on their performance in a reading test and interviewed to gain more insight into their reading experiences. The questionnaires were analysed using the t-test, and the interview responses were analysed by content analysis. The findings show that students had benefited from ER. Questionnaire results show that students' reading habits had improved significantly. The reports from the interviews and inventories show that students' affective and cognitive reading levels, including reading speed, had also improved. Students also reported on the transfer of reading strategies from their ER to their academic reading. Based on the findings, recommendations are made for reading programmes at the tertiary level, specifically at this institution, to include ER in order to complement explicit teaching, instil motivation and accelerate the improvement of students' reading proficiency.

\section{Introduction}

Reading is fundamental to learning. Reading researchers concur that reading underlies all forms of academic study and is crucial to academic success (Alderson 2000; Grabe \& Stoller 2011; Guthrie 2008; Pretorius 2000). Scott and Saaiman (2016) state that reading is an indispensable skill and is fundamentally interrelated with educational success. The various types of reading, such as reading for pleasure, skimming or reading to learn, all contribute to learning (Grabe \& Stoller 2011). Reading for pleasure or extensive reading (ER), among other types of reading, such as reading to learn, helps to improve students' reading proficiency and increases their metacognitive skills (Grabe 2009; Horst 2005). Reading for pleasure also complements formal reading instruction in the classroom and increases reading comprehension skills. However, given the 21st-century over-dependence on electronic devices, a number of university students in South Africa have not, and still do not, read for pleasure, as evidenced in a study by Boakye and Southey (2008). The situation becomes complex for a number of students from low socio-economic status homes because of a lack of resources and reading materials (Currin \& Pretorius 2010; Pretorius \& Mampuru 2007). These students do not experience joy and pleasure or personal satisfaction when reading and, consequently, have not developed positive reading habits. As a result, when students are faced with the quantity and level of reading required at tertiary level, they are overwhelmed (Boakye 2012; Niven 2005).

Given the poor reading instruction in a number of schools, print-poor environment at home and lack of emphasis on reading at school level (Currin \& Pretorius 2010; Pretorius \& Lephalala 2011; Van Staden \& Howie 2010; Zimmerman \& Long 2008), a number of students in South Africa's tertiary institutions do not only lack appropriate reading strategies but also have low motivation and little or no love of reading (Boakye \& Southey 2008). Thus, without adequate levels of reading proficiency, students are not adequately equipped for academic literacy requirements at tertiary level. A body of research (e.g. Horst 2005; Savas 2009) has shown the enormous benefits of ER in improving reading proficiency. According to Savas (2009:66), English for Academic Purposes (EAP) courses for tertiary education may not meet the needs of students fully, or maximise the improvement of language and reading proficiency, and would have to be complemented with ER. However, ER is lacking in many reading programmes (Grabe 2009) and more so at tertiary level. 
Studies on ER at university level are minimal, especially studies pertaining to L2 speakers (Brunfaut 2008; Grabe 2009; Grabe \& Stoller 2011) in African countries. The article reports on a study that focused on ER among first-year students at a tertiary institution in South Africa. ER was integrated into a reading intervention programme, thus combining intensive reading and ER in the programme. The intervention programme consisted of various cognitive and affective strategies and an ER component to further support the reading instruction of the cohort of students. The ER component was evaluated mainly through interviews with selected students and is reported on in this article.

The article first discusses the benefits and characteristics of ER and various studies conducted on ER. Thereafter, the article reports on the study by providing various excerpts of students' accounts and responses during interviews as well as quantitative results of a questionnaire on reading habits. The article concludes with recommendations that advocate for the inclusion of ER in reading intervention programmes.

\section{Extensive reading}

Extensive reading is sometimes referred to as pleasure reading (Day \& Bamford 2009), sustained silent reading (Garan \& DeVooged 2008) or free reading (Krashen 2004). This form of reading is receiving attention as an effective reading instruction for L2 learners (Grabe 2009; Grabe \& Stoller 2011; Nation 2009; Yamashita 2004). ER instruction requires students to read large quantities of texts for general understanding and for pleasure (Grabe 2009). Reading is individualised and independent, but students can discuss common texts in a group or as a community. Savas (2009) and Haider and Akhter (2012) argue that ER enables students to take responsibility for reading outside the classroom and develop reading autonomy.

Students are given the option to select texts based on their own interest and proficiency level (Bamford \& Day 2004; Kirin, Poolsap \& Plongthong 2012; Yamashita 2008). The goal of ER is to get students to enjoy reading in the target language (Savas 2009). Whereas intensive reading (IR) aims to develop students' reading skills explicitly by teaching strategies, such as identifying main ideas, recognising text signals and finding meaning of words (Haider \& Akhter 2012; Savas 2009), ER encourages reading of comprehensible texts for pleasure.

\section{Characteristics of extensive reading}

Extensive reading has been described by various researchers on the basis of its distinctive features. The characteristics of ER listed by Day and Bamford (1998) include the following:

- Students read large amounts of printed material.

- The material they read falls in their level of comprehension.

- They choose their own reading material.

- Teachers are to read with students to serve as role models and provide enthusiasm.

- Reading is its own reward - reading is for pleasure, information and general understanding.
- Reading is done at a faster rate.

- Reading is individual (students read on their own); teachers guide and monitor students.

- Follow-up post-reading activities can be given to students.

- Teachers and students keep track of students' progress.

Issues such as choice, role models, comprehensible texts and no formal assessments are important features of ER. In other words, it is important for students to be given the opportunity to choose what they want to read; for teachers, parents and other significant adults to serve as role models; for texts to be within students' level of competence; and to have no formal assessments. Follow-up activities could be given to replace formal assessments. However, the best practice is for the activity not to be assessed at all. ER among L2 speakers can be underpinned by three theoretical frameworks, viz. the linguistic interdependence hypothesis (LIH), the linguistic threshold hypothesis (LTH) and the transfer hypothesis.

\section{Theoretical framework}

The LIH by Cummins (1979) and the LTH by Clarke (1980) posit that students can transfer L1 reading skills to L2 reading, provided that they have reached a language threshold in the L2. The threshold according to Grabe and Stoller (2011) depends on context (i.e. the level of difficulty, the text itself and the nature of the task). However, a number of students may have done little or no reading in their L1 to transfer to the L2 (August 2006), and a greater number may not have reached the L2 threshold for tertiary level reading, or for the type of reading tasks required at this level. Yeld (2009) convincingly shows that many students lack the required academic literacy skills for tertiary education and are at the basic or intermediate level, instead of the proficient level. In addition to the LIH and LTH, the transfer hypothesis of Hacquebord (1989) states that students would benefit from ER if they continue reading in the L1 while reading in the L2. However, a number of students have not and do not read in their L1. These three hypotheses may not be applicable to a number of tertiary level students in the country, as the majority have done minimal reading in L1 (Boakye \& Southey 2008) and a number have not reached the tertiary threshold (Yeld 2009). In addition, given the fact that students' motivation to read decreases as they move up the education ladder (Guthrie \& Wigfield 2000), it can be assumed that very little L1 reading would have taken place before and during tertiary study. It would therefore seem that there is a lack of reading culture among many tertiary students. ER therefore becomes one of the important avenues of developing reading proficiency among tertiary students.

\section{According to De Castell (1981):}

[a] person is literate when he has acquired the essential knowledge and skills which enables him/her to engage in all those activities in which literacy is required for effective functioning in his/her group of community. (p. 8)

In other words, university students need to be proficient readers to acquire new knowledge and function in the 
academic community. A reading programme that aims to develop such literacy is the most beneficial for reading development and contributes to more successful learning (Savas 2009). Thus, a programme that incorporates ER and leads to independent reading would seem to be more adequate than one that is mainly IR driven without ER.

\section{Benefits of extensive reading}

Extensive reading has many benefits, including the improvement of fluency, reading ability, vocabulary, writing and grammar (Grabe 2009; Huang \& Liou 2007; Yamashita 2008). It has been shown to improve reading comprehension, increase vocabulary development and improve reading and writing skills and abilities (Day \& Bamford 2009; De Jong \& Bus 2002; Huang \& Liou 2007). Through reading books, a number of important changes occur in learners' academic literacy. Savas (2009) states that an EAP programme that includes ER is a 'new type of reading instruction' and is more effective than an EAP teaching that is based on IR alone. Mckool and Gespass (2009) actually perceive reading instruction without ER as counter-productive to developing students' reading ability. According to the input hypothesis of Krashen (1988:278), successive reading enables the learner to be repeatedly exposed to new words and expressions, as well as other aspects of discourse, while extending and deepening their understanding of more familiar ones. Warring and Takaki (2003) intimate that ER helps to consolidate strategies that learners know of or have been taught. For example, through constant, continuous and substantial exposure to texts, students acquire the sense of how the language is structured, including organisation of discourse and the use of prepositions. ER is therefore regarded as one of the most effective ways to enhance reading speed, comprehension and vocabulary because of the amount of repeated exposure to interesting and meaningful L2 reading material (Asraf \& Ahmad 2003; Hitosugi \& Day 2004; Kirin et al. 2012; Yamashita 2008).

Extensive reading holds many benefits for students' reading proficiency. Reading for pleasure contributes to the development of students' reading ability by unconsciously increasing their reading speed and improving their use of strategies. In addition, it helps to instil a love for reading and promotes independent reading. Furthermore, as a number of students are first-generation or non-traditional (August 2006) students, who may not have done much reading in the home language or in the target language (English), ER will help develop these students' love of reading, motivation to read and joy in reading. Explicit strategy instruction and comprehension strategies alone may not be adequate to improve students' overall reading ability in the limited time that they receive instruction in support programmes. Krashen (2004) points out that ER is a major source of acquiring reading competence, vocabulary and the ability to handle (productively and receptively) complex grammatical constructions.

A number of studies have shown the benefits of ER. Hayashi (1999) investigated the relationship between reading ability and the amount of reading undertaken in ER by first-year students and found that ER effectively helped improve the ability to comprehend what is read, as well as their vocabulary. Yamashita (2008) explored the effect of ER on language proficiency, including general reading ability, using 31 Japanese university freshmen. They found a great improvement in the reading ability of this cohort of English Second Language speakers. ER contributes to improvement in both affective and cognitive reading.

\section{Affective benefits}

Affective aspects of reading, such as motivation, interest, attitude and self-efficacy, are increased through ER. Powell (2005) found that reading for pleasure not only develops reading ability but also benefits a range of affective aspects, such as boosting confidence and self-efficacy, increasing motivation and improving students' overall attitude towards reading. Chen et al. (2013) point out that ER can enhance the reading attitude of L2 students immensely. Safaeia and Bulca (2013) found that students' in ER programmes developed stronger self-confidence to internalise what they had read. Deci and Ryan (2000) intimate that ER encourages autonomy, which leads to enhanced motivation and improved learning. Mason and Krashen (1997) found that the majority of students who were reluctant readers became eager readers as a result of ER. Using a questionnaire, Sun (2003) investigated 59 university students' attitude towards ER. Students reported positive attitudes towards the ER programme and improvement of language skills. In addition, independence and autonomy were established in L2 reading. Arnold (2009) also reported on students' gains as a result of ER. Using first-year students in a German class he found that students reported an increase in reading motivation, attitude, confidence, reading ability and reading for pleasure outside class.

\section{Cognitive benefits}

Cognitive benefits of ER, such as comprehension, vocabulary development, discourse organisation and sentence structure, have been shown in various studies. Savas (2009) found that compared to the control group the ER group's reading comprehension and vocabulary increased. The exception was grammatical knowledge in which the control group received explicit instruction. He concludes that ER in EAP programmes makes the programme more beneficial than IR that focuses only on strategy instruction by means of academic texts. ER, which encourages autonomous learning, therefore seems to be the best means of accelerating vocabulary development. Huang and Liou (2007) used 16 articles to construct an English ER programme. The programme was conducted with 38 college students over 12 weeks. The pre- and post-test results showed that participation in the reading programme improved learners' vocabulary scores. Carrel and Carson (1997:49) point out that IR and ER should not be seen as opposing teaching approaches, but that each serves different but complementary purposes and that both should be used in reading programmes.

\section{Transfer benefits}

As explained by the LIH and the transfer theory of Hacquebord (1989), reading skills can be transferred from L1 
to L2. Transfer of skills can also take place from ER to IR. A number of studies show that students can transfer skills acquired in ER to academic reading in their subject areas. Savas (2009) explains that ER results in a spread effect of reading competence to other language skills such as writing and control over syntax. Day and Bamford (2009) show the transfer of vocabulary development and writing skills. Using the reading attitude questionnaire and TOEFL's reading comprehension and vocabulary test, Chen et al. (2013) found that the experimental group showed a significantly better reading attitude, reading comprehension and vocabulary knowledge than the control group. They concluded that ER attributes transfer to academic reading and should be incorporated into tertiary reading programmes to help improve tertiary level L2 students' reading attitude, reading comprehension and vocabulary knowledge (Chen et al. 2013).

Other studies, such as those by Horst (2005), Hitosugi and Day (2004), Powell (2005) and Rodrigo et al. (2007), have shown students' transfer of cognitive and affective reading improvement to academic reading. In South Africa, the study by Scott and Saaiman (2016) is one of a small number of ER studies at tertiary level.

Despite research proving the benefits of ER in students' affective and cognitive reading elsewhere, studies in South African tertiary institutions and in Africa generally are limited. The reading and writing needs of students in Africa and, in particular, South Africa may differ from those of students in Asia, Europe and America. In addition, most studies have either used solely questionnaires or pre- and post-tests to assess the benefits of ER quantitatively. While these methods of data collection can be quantified and are necessary, qualitative accounts provide an in-depth assessment and evaluation of ER and provide deeper insight into how students benefit from this activity. The study used questionnaires to a limited extent, but mainly interviews and inventories to ascertain students' views on the benefits or lack thereof of ER on students' affective and cognitive reading abilities.

The aim of the study was therefore to explore students' opinions of the ER component of the intervention. In addition, the researcher aimed to find out if students at tertiary level, specifically those at this institution, benefit from ER. The questions that informed the study were the following:

RQ1. What are the opinions and perceptions of students regarding the ER component of the reading intervention programme?

RQ2. Did this cohort of students benefit from ER? If so, how?

\section{Methodology}

The intervention conducted for the study comprise affective and cognitive teaching techniques (i.e. learning goal, collaboration, interesting texts, praise and rewards, autonomy support, strategy instruction, teacher support and ER), to teach and improve students' reading proficiency (See Boakye 2017 for details of the intervention programme). ER was included in the programme to complement instruction and to promote engaged reading where students are involved in the texts to achieve affective and cognitive improvement in reading. Students were to read for pleasure on a weekly basis and to record their affective and cognitive experiences (improvements and challenges) in an inventory. They chose their own reading texts, for example, short stories or novels. In a scaffolded manner they were to read shorter texts that were at their level of competence of a minimum of 50 pages each week for 2 weeks and progress to longer, more challenging texts of a minimum of 100 pages each week for the rest of the semester. Thus, for most of the semester the readings were to be longer and mainly novels. Furthermore, students were to time and monitor their reading and record any affective and cognitive improvements and challenges.

The intervention was conducted in the first semester and lasted 14 weeks for high-risk students and 7 weeks for lowrisk students. The comments were intended to indicate challenges encountered by students while reading (e.g. difficulties in comprehension and associated boredom and the positive experiences (e.g. improvement in comprehension, increase in speed, pleasure and involvement in the readings). In essence, students were to provide cognitive, metacognitive and affective reflections on their readings.

\section{Participants}

The study comprised two groups of first-year university students who were categorised as high-risk or low-risk based on their performance in a literacy test. Each group had a control equivalent. Although the entire cohort of students were required to complete the questionnaire, participants for the interviews were selected by purposive sampling. All the students in the two groups wrote a reading test and those who obtained the highest, average or lowest scores in the reading test were identified and selected for interviews. Thirty-six students were interviewed.

\section{Instrument}

Pre- and post-intervention questionnaires on students' reading habits before and after the intervention were administered to determine if students' ER habits had improved after the intervention. Semi-structured interviews were used to gain a better understanding of the effectiveness of the intervention as perceived by the students. Interview questions probed students' opinions of the affective and cognitive benefits of the ER component of the intervention. Inventories written by students on their affective and cognitive experiences during the reading activity shed more light on their reading challenges and improvements. The data from the interviews and the inventories are presented qualitatively.

The semi-structured interview questions were based on the reading activity of students. Questions used for the interview on ER included the following:

- Did ER influence your reading ability, and if so, in what way?

- Do you feel that you have been motivated to read more often? 
- Did the ER that you had to do influence your reading behaviour or habits in any way?

- When you read novels, do you identify with characters (e.g. share their pain, joy, and so on)?

- Were you involved in the reading of the novel or text?

- Did you become curious about the unfolding of events in the novels?

- Did ER benefit you in any way? Explain how.

Besides the specific questions, students were also asked to provide general comments on the activity:

- Comment briefly on any challenges, improvements and developments, and provide suggestions if necessary.

\section{Questionnaire}

The questionnaire comprised five questions on how frequently students read and what kind of texts they read (see Table 1).

\section{Procedure}

The selected students were interviewed for approximately 15 min each at the end of the intervention.

Students completed the questionnaires on reading habits before and after the intervention. Students submitted their inventories at the end of the intervention.

\section{Data analysis}

Firstly, the pre- and post-intervention questionnaires on reading habits were compared using means and $t$-test analyses to determine any improvement in their reported reading habits. The Cronbach's alpha for the questions on reading habits was 0.68 , which was considered adequate for a group analysis to be made.

Secondly, the interviews were recorded and transcribed. Notes were also taken manually, and the two were tallied. Thereafter, the responses were coded and grouped under affective and cognitive themes and other significant salient themes that emerged (Ivankova \& Cresswell 2009). The number of students who referred to a specific issue was converted to a percentage by dividing the overall number of students interviewed and multiplying by 100. Pseudonyms are used for the presentation by substituting English, Afrikaans and African names with similar ones.

Thirdly, examples were taken from the inventories. These are included to provide more insight into students' affective and cognitive reflections on their ER.

\section{Findings}

Whereas the data for the questionnaires are presented to show statistical improvement, the interview reports and the examples from the inventories are given to indicate improvements verbally and to provide further insight into how ER helped to improve students' reading proficiency, as reported by them. The three data sets are provided for corroboration.

\section{Questionnaires}

The means and the $t$-test analysis of the questionnaire results showed that students' reading habits had improved significantly after the ER intervention. The means for the pre-intervention were 2.43 for the high-risk and 2.67 for the low-risk group. After the intervention, these had improved to 1.82 and 2.22, respectively. Lower mean figures indicate more positive responses. The improvements were statistically significant at $(t(74)=-5.11$, $p=0.000)$ for the high-risk group and significant at $(t(117)$ $=5.36, p=0.000$ ) for the low-risk group. The results are shown in Figure 1.

The control groups, which had had no intervention, slumped to mean figures of 2.71 and 2.73 in the high-risk and low-risk groups, respectively.

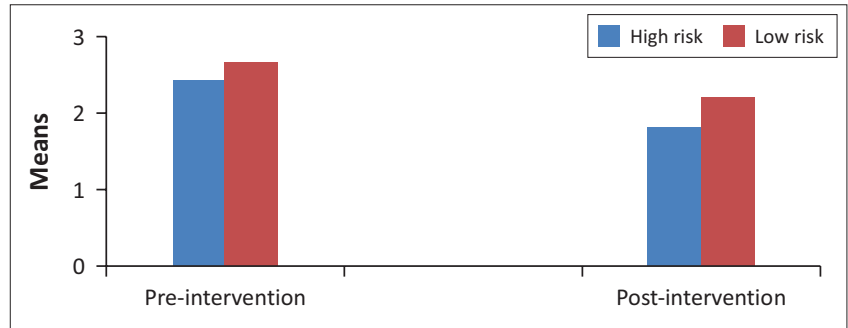

FIGURE 1: Pre- and post-intervention results regarding students' extensive reading habits.

\section{TABLE 1: Questions on students' reading habits.}

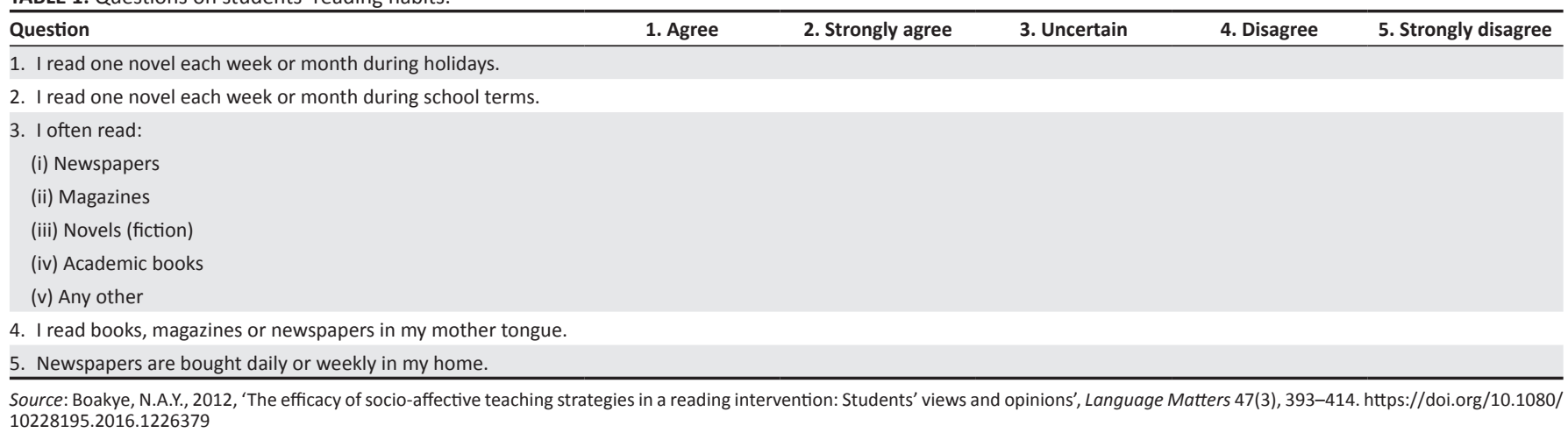




\section{Interviews}

Students reported great improvement in cognitive and affective reading levels. They also reported transfer of reading strategies and improvements in reading speed. Firstly, the findings for the high-risk group are given, after which the low-risk group is reported on.

\section{High-risk group}

Because of the voluntary nature of the ER component, $56 \%$ of the students in the high-risk group did not participate. The main reasons cited for non-participation were poor time management and inability to cope with academic work. Three of the four students who obtained the lowest marks in this group did not participate. However, the fourth student, who participated, improved his pre-test mark to an average mark in the post-test. Those who participated in the ER reported as follows:

- $43 \%$ reported improvement in reading habits and general reading proficiency.

- $86 \%$ reported improvement in comprehension.

- $56 \%$ reported on the affective aspect of being deeply involved in the story and in the reading of the novel, in a sense engagement in reading.

- $100 \%$ reported an increase in reading speed and vocabulary.

On a more specific level, one student reported that she started reading simply as a stress reliever at the end of her daily lectures, intended merely to meet the requirements set by the lecturer. However, she realised at the end of the activities that she had benefited immensely. First of all she could focus for longer while reading, whereas initially her mind used to wander when she studied. She reported that she previously lacked concentration and focus in reading, but obtained these while reading for pleasure. On transfer of skills, she stated that she was surprised to find that this ability had transferred to her other modules as well, and her mind no longer wandered when studying. Secondly, her reading speed increased, which motivated her and increased her willingness to read more, as indicated in the following self-report:

'I used the reading to relieve stress from attending lectures all day. I did not like reading but undertook the reading project because we were asked to do so. My mind used to wander when I am studying, but when I started reading the book it did not happen and now I can study without my mind wandering. I realised that I was reading faster than before and this encouraged me to read more. I felt like I could read more and more. I became so involved in a motivational book I was reading that I started practising the suggestions.' [Ndlovu, student]

From Ndlovu's self-report, cognitive and affective benefits are integrated and influence each other. Phalane, who had not been reading before the project, remarked:

'I could not wait to finish and find out the end of the story.' [Phalane, student]

One student confessed that she found the reading difficult initially, but as she continued, she began to enjoy it and became very interested in the novels. She reported that her understanding improved and her imagination was very active as she became involved in the story. She added that she felt good because she was aware of her progress. Her newly developed activity of reading for pleasure influenced her reading of academic texts. She admitted during the interview session that she used to dislike her Marketing module because it required too much reading, but now enjoyed reading and also had better understanding of what she read:

'I felt good because I could see my progress. At the beginning I found reading difficult but I continued and I started enjoying it. I borrowed more books from the lecturer so that I could continue reading even after the project. I realised that I could understand better. My imagination was involved in the reading. It influenced my reading in other subjects. For example, I used to hate Marketing because of the reading, but now I enjoy reading my textbooks and I also understand it better than before.' [Aphane, student]

Similar to that of Ndlovu, Aphane's report pointed to cognitive and affective benefits, which shows that the two are interdependent in ER. ER provided joy and love for reading, leading students to read more. As they continued to read daily for pleasure, frequent reading improved their comprehension and other reading skills. The awareness of this improvement increased their confidence and self-efficacy and instilled higher motivation. Consequently, they read even more, which contributed to higher reading proficiency.

\section{Low-risk group}

In the low-risk group, $50 \%$ of the students did not participate in ER. Reasons given were similar to those of the high-risk students, namely being overburdened by academic work. However, one student, Webb, explained that he was just not interested in reading. This was shown in his performance, as he was one of those who obtained the lowest mark in the pretest. Another student, Maluleka, who was one of those who obtained the highest pre-test mark, explained that he did not participate because he did not think he needed it. Similar sentiments were expressed by some students in the study by Scott and Saaiman (2016). It seems some students do not perceive ER favourably. For the other $50 \%$ who participated, the benefits were considerable. They reported improvement in areas such as comprehension, reading speed, motivation, self-efficacy, interest and involvement, as follows:

- $75 \%$ increase in reading speed and understanding

- $50 \%$ transfer of reading improvements to reading of textbooks in other subjects

- $25 \%$ increase in vocabulary and improvement in the use of reading strategies motivated them to read more

- $38 \%$ involvement in the stories and enjoyment of reading

- $25 \%$ confidence in reading

- $50 \%$ development of interest and motivation, which instilled willingness to read

- $50 \%$ desire to read frequently, especially during the holidays

A number of students (38\%) reported being involved in what they read. They explained that they had to make the time to 
read, but once they did, they enjoyed it and became involved. A student stated succinctly:

'I had to force myself to start reading but once I started I found I became involved and enjoyed it. Then I had to force myself to stop so that I can study. It's like I am in the story.' [Botha, student]

Botha added that her reading speed and comprehension improved. She also admitted that as an Afrikaans L1 speaker she had read only Afrikaans non-academic texts, and therefore found the vocabulary in the novels challenging. However, as she searched on Google and consulted a dictionary to find the meaning of words, she realised that her vocabulary was improving and the unfamiliar words were becoming fewer and fewer as she read. She reported that her motivation to read increased as she became involved in the story and enjoyed reading and added that she would be reading more English books during the June holidays. When asked for her general comment on the ER project, she reported that her vocabulary and her ability to read English texts had improved, which had resulted in boosting her confidence in reading English novels and that for the LLB programme she was registered for, she intended to switch from Afrikaans instruction to English instruction the following year. Another student reported that she 'was not much of a reader', but after the intervention, she had been reading a lot since she got into the habit as a result of the reading project. She added that the reading project had helped to improve her reading speed and comprehension:

'I saw improvement in my reading speed from the weekly recordings. I was not much of a reader, but now I read a lot. Because I am reading frequently now, and using the correct strategies, I can see that it has improved my understanding. I understand what I read better.' [Mogomotsi, student]

\section{Inventories}

The inventories consisted of affective comments such as involvement, motivation and interest, and cognitive comments on vocabulary, comprehension and improvement in general reading ability. Some examples are given below:

'The novel was initially difficult to read but became easier as I progressed.' [Naidoo, student]

'I have learned few terminologies from the book and my vocabulary has expanded as a result.' [Mashimbye, student]

On affective comments some students wrote:

'I felt immediately related to one of the characters in the book; that even stimulated me to read more and I enjoyed reading the book. I wanted to read more of the book every day.' [Ditshego, student]

'No text is this funny or exciting. Throughout my reading, boredom was absent, pleasure and excitement were present.' [Mashimbye, student]

'I felt excited and sometimes scared as though I was in the story.' [Rudman, student]

'My emotions were greatly stimulated, I felt like I was in the book, the author had my pulse racing.' [Saunders, student]

'I had negative feelings. Was worried, sad, depressed but I enjoyed the book and didn't want to stop reading.' [Kahts, student]
'It involves imagination to a large extent. Interaction with the novel and the author's thoughts made reading the book enjoyable. Cognitive skills are required for understanding the development of the story in To kill a Mockingbird.' [Mashigo, student]

The main challenge documented was difficulty with vocabulary:

'Difficulty with vocabulary (big words made it difficult to commit and be involved).' [Mamadi, student]

'Difficult to understand because of some of the vocabulary but easy as soon as the meaning of some of the difficult words became clear.' [Coetzee, student]

These reports from the inventories corroborated the interview responses and pointed to affective and cognitive benefits of ER.

\section{Discussion}

The majority of the students (86\% at risk; $75 \%$ low-risk) reported that they observed great improvement in speed and comprehension as they progressed with the reading. They also reported that the ER project had helped to improve their use of reading strategies and had increased their understanding of texts, which they had transferred to the reading of their textbooks. Another perception was that students found reading to be addictive. Once they begun the activity and immersed themselves in it, they could not stop. They reported that the freedom to select their own texts was motivating. An increase in reading speed was also motivating and encouraged them to read more. As their reading speed increased, they reported an increase in comprehension, which compounded their motivation. In turn, students' motivation and willingness to read increased. They read frequently, and as they read, they became involved and engaged. By reading frequently and being involved, they improved their reading ability. As stated by Grabe and Stoller (2011), reading ability improves with frequent reading. These responses confirm the claim by Guthrie and Wigfield (2000:404): ‘[A]s students become engaged readers, they provide themselves with selfgenerated learning opportunities that are equivalent to several years of education.'

When students were given the opportunity to comment on the intervention as a whole, a number of them $(40 \% \mathrm{HR}$ and $29 \%$ LR) specifically mentioned improvement in their reading habits as a direct result of ER. The results of the $t$-tests show that students' reading habits had improved significantly.

The interview responses show that students in both the high-risk and low-risk groups gave similar responses to questions on ER. In general, students from both groups responded positively to ER questions, which imply cognitive, affective and transfer gains. From their comments it can be inferred that the ER component had helped to improve their reading ability, which had influenced their self-efficacy and further increased their motivation. Thus, results from both quantitative and qualitative data showed that students had developed positive affect for reading and had improved their reading ability. 
In answer to question 1: 'What are the opinions and perceptions of students regarding the ER component of the reading intervention programme?', students' responses show that for those who participated, ER had helped to improve their cognitive and affective reading levels. Students had become involved in their reading and had become engaged readers. The awareness of progress also increased their selfconfidence and self-efficacy. This relationship between selfefficacy and metacognitive knowledge is confirmed by several researchers (Grabe \& Stoller 2011; Guthrie \& Wigfield 2000; Pajares 2006). Coutinho (2008) concluded from her study that students with effective metacognition also showed strong beliefs in their capability to successfully perform reading tasks.

In answer to question 2: 'Did this cohort of students benefit from ER? If so, how?', the qualitative data from the interviews and from the inventories indicate that students had gained from the ER project. The data also shed light on how students had benefited from the ER component of the intervention. Students' responses can be grouped into three main categories: academic or cognitive improvements, transfer benefits and affective improvement. These academic or cognitive and affective gains increased students' motivation, which encouraged them to read, thus developing their reading proficiency and consequently also their academic performance.

When students' motivational levels increased as a result of $\mathrm{ER}$, they became engaged readers and their reading ability improved, which led to even higher motivational levels, which further influenced their reading ability. Thus, ER could be said to have had a positive influence on students' motivation, self-efficacy, attitudes and enjoyment and had improved their reading comprehension and reading speed, as well as facilitated their transfer of skills from ER to academic reading.

The aim of the inclusion of ER in the intervention programme was to cultivate independent, engaged readers who would have a love for reading and would develop positive reading habits and reap cognitive and affective gains to improve their reading proficiency. To achieve this, students selected their own texts and read in their own time in a scaffolded manner. The results confirm that ER leads to cognitive and affective gains in reading. This type of reading should therefore be included in reading programmes in order to maximise the development of students' reading proficiency and consolidate explicit reading instruction.

The article argues that cognitive-oriented reading instruction should be extended to include ER in order to provide more students with the opportunity to read for pleasure. The inclusion of ER will provide students with the opportunity to improve their reading proficiency in a more pleasurable, less demanding way and enable them to acquire a lifelong love of reading. It would also help to improve students' reading ability and complement reading instruction. In addition, ER will help to develop engaged readers. According to Guthrie and Wigfield (2000), engaged readers are strategic readers who employ well-orchestrated strategies to achieve comprehension. Engaged readers are successful readers. They improve their reading ability by being deeply involved in what they read.

Even at tertiary level where students are supposed to engage with academic texts on a higher level and may also not have time to read for pleasure, ER can be introduced depending on the type of books and how the ER component is integrated into the programme. This approach will further help to improve students reading proficiency and inculcate lifelong readers. The argument often put forward is that students at tertiary level do not have time to engage in ER and that because of lack of time, attention should be focused on teaching strategies and using academic texts. This study has shown that ER complemented academic reading instruction and facilitated reading development in this cohort of tertiary students in Africa.

\section{Conclusion}

This article has provided insight into how ER helped improve students reading proficiency and develop their love for reading. It provided an in-depth understanding of how students experienced the ER incorporated into a reading intervention programme. The data from the interviews showed that students felt that they were highly motivated to read and were willing to read, which improved their reading proficiency. The data also show that the students believed that they had developed a positive attitude and increased interest in reading as a result of ER. In addition, students reported being involved (engaged) in their ER and transferring these skills to academic reading. Furthermore, they linked the affective developments to the positive developments in their reading ability, such as increased reading speed and comprehension. It can therefore be concluded from the findings that ER increased students' affective levels in reading, as well as their reading habits and reading proficiency in both pleasure reading and academic reading. The study on ER was part of a broader reading intervention programme. A similar study confined to the use of ER alone is recommended for future study, in order to evaluate the influence of ER more specifically.

\section{Acknowledgements Competing interests}

The author declares that she has no financial or personal relationship(s) which may have inappropriately influenced her in writing this article.

\section{References}

Alderson, J.C., 2000, Assessing reading, Cambridge University Press, Cambridge.

Arnold, N., 2009, 'Online ER for advanced foreign language learners: An evaluation study', Foreign Language Annals 42(2), 340-366. https://doi.org/10.1111/j.19449720.2009.01024.x

Asraf, R.M. \& Ahmad, I.S., 2003, 'Promoting English language development and the reading habits among students in rural schools through the guided ER programme', Reading in a Foreign Language 15, 83-102. 
August, G., 2006, 'So what's behind adult English second language reading?', Bilingual Research Journal 30(2), 245-264. https://doi.org/10.1080/15235882. 2006.10162876

Bamford, J. \& Day, R.R., 2004, ER activities for teaching language, Cambridge University Press, Cambridge.

Boakye, N.A.Y., 2012, 'The efficacy of socio-affective teaching strategies in a reading intervention: Students' views and opinions', Language Matters 47(3), 393-414. https://doi.org/10.1080/10228195.2016.1226379

Boakye, N.A.Y., 2017, 'Efficacy of a reading intervention for first-year university students', Per Linguam 33(1), 1-24. https://doi.org/10.5785/33-1-710

Boakye, N.A.Y. \& Southey, L., 2008, 'Investigating students' motivations and attitudes towards reading', Language Teaching Research 42(2), 7-24.

Brunfaut, T., 2008, 'Foreign language reading for academic purposes', Unpublished doctoral thesis, University of Antwerp, Antwerp.

Clarke, M., 1980, 'The short circuit hypothesis of ESL reading - Or when language competence interferes with reading performance', The Modern Language Journal 64(2), 203-209. https://doi.org/10.1111/j.1540-4781.1980.tb05186.x

Carrel, P.L. \& Carson, J.G., 1997, 'Extensive and intensive reading in an EAP setting', English for Specific Purposes 16, 47-60. https://doi.org/10.1016/S0889 4906(96)00031-2

Chen, C.-N., Chen, S.-H.E., Chen, S.C. \& Wey, S., 2013, 'The effects of ER via e-books on tertiary level EFL students' reading attitude, reading comprehension and vocabulary', The Turkish Online Journal of Educational Technology 12(2), 303-312, viewed 15 March 2016, from http://www.tojet.net/articles/v12i2/12228.pdf

Coutinho, S., 2008, 'Self-efficacy, metacognition \& performance', North American Journal of Psychology 10(1), 165-172.

Cummins, J., 1979, 'Linguistic interdependence and the educational development of bilingual children', Review of Educational Research 49(2), 222-251. https://doi. bilingual children', Review of Educationc
org/10.3102/00346543049002222RE

Currin, S. \& Pretorius, E.J., 2010, 'The culture of the sharp pencil: Can a literacy intervention lever school change?', Reading \& Writing 1(1), 23-46.

Day, R.R. \& Bamford, J., 1998, ER in the second language classroom, Cambridge University Press, New York.

Day, R.R. \& Bamford, J., 2009, ER in the second language classroom, Cambridge University Press, Cambridge.

De Castell, S., 1981, 'On defining literacy', in S. de Castell, A. Luke \& K. Egan (eds.), Literacy, society and schooling, pp. 7-18, Cambridge University Press, Cambridge.

Deci, E.L. \& Ryan, R.M., 2000, 'Self-determination theory and the facilitation of intrinsic motivation, social development and well-being', American Psychologist 55, 68-78. https://doi.org/10.1037/0003-066X.55.1.68

De Jong, M.T. \& Bus, A.G., 2002, Quality of book-reading matters for emergent readers: An experiment with the same book in a regular or electronic format, Cambridge University Press, Cambridge.

Garan, E.M. \& DeVooged, G., 2008, 'The benefits of sustained silent reading: Scientific research and common sense converge', Reading Teacher 62(4), 336-344. https:// doi.org/10.1598/RT.62.4.6

Grabe, W., 2009, Reading in a second language: Moving from theory to practice, 2nd edn., Cambridge University Press, Cambridge.

Grabe, W. \& Stoller, F.L., 2011, Teaching and researching reading, 2nd edn., Pearson Education, Harlow.

Guthrie, J.T., 2008, 'Reading motivation and engagement in middle and high school: Appraisal and intervention', in J.T. Guthrie (ed.), Engaging adolescents in reading, pp. 1-16, Corwin Press, London.

Guthrie, T. \& Wigfield, A., 2000, 'Engagement and motivation in reading', in M.L. Karmil, P.B. Mosenthal, P.D. Pearson \& R. Barr (eds.), The handbook of reading Karmil, P.B. Mosenthal, P.D. Pearson \& R. Barr (eds.), The hand
research, vol. III, pp. 403-420, Lawrence Erlbaum, Mahwah, NJ.

Hacquebord, H., 1989, Reading comprehension of Turkish and Dutch students attending secondary schools, RUG, Groningen.

Haider, M.Z. \& Akhter, E., 2012, 'Extensive reading in EFL classroom at secondary schools in Bangladesh: Current practices and future possibilities', International Education Studies 5(3), 126-133. https://doi.org/10.5539/ies.v5n3p126

Hayashi, K., 1999, 'Reading strategies and ER in EFL classes', RELC Journal 30(2), 114132, https://doi.org/10.1177/003368829903000207

Hitosugi, C. \& Day, R.R., 2004, 'ER in Japanese', Reading in a Foreign Language 16, 20-30.

Horst, M., 2005, 'Learning second language vocabulary through ER: A measurement study', The Canadian Modern Language Review 61, 355-382. https://doi.org/ 10.3138/cmlr.61.3.355
Huang, H.T. \& Liou, H.C., 2007, 'Vocabulary learning in an automated graded reading program', Language Learning \& Technology 11(3), 64-82.

Ivankova, N.V. \& Creswell, J.W., 2009, 'Mixed methods', in J. Heigham \& R.A. Croker (eds.), Qualitative research in applied linguistics: A practical introduction, pp. 135-161, Palgrave Macmillan, London.

Kirin, W., Poolsap, P. \& Plongthong, J., 2012, 'Promoting ER among Chinese students learning Thai as a foreign language', Procedia Engineering 32, 1178-1182. https:// doi.org/10.1016/j.proeng.2012.02.074

Krashen, S.D., 1988, Stephen Krashen's theory of second language acquisition, viewed 10 May 2016, from http://www.sk.com.br/sk-krash-english.html

Krashen, S.D., 2004, 'Free voluntary reading: New research, applications, and controversies', Paper presented at the RELC Conference, Singapore, April, viewed 20 September 2016, from http://www.sdkrashen.com/content/articles/ singapore.pdf

Mason, B. \& Krashen, S.D., 1997, 'ER in English as a foreign language', System 25(1), 91-102. https://doi.org/10.1016/S0346-251X(96)00063-2

McKool, S.S. \& Gespass, S., 2009, 'Does Johnny's reading teacher love to read? How teachers' personal reading habits affect instructional practices', Literacy Research and Instruction 48, 264-276. https://doi.org/10.1080/19388070802443700

Nation, I.S.P., 2009, 'Reading faster', International Journal of English Studies 9(2), 131-144.

Niven, P.M., 2005, 'Exploring first year students' and their lecturers' constructions of what it means to read in a humanities discipline: A conflict of frames?', South African Journal of Higher Education 4(19), 777-789.

Pajares, F., 2006, 'Self-efficacy during childhood and adolescence: Implications for teachers and partners', in F. Pajares \& T. Urden (eds.), Self-efficacious beliefs of adolescents, pp. 339-367, Information Age Publishing, Greenwich, CT.

Powell, S., 2005, 'ER and its role in Japanese high schools', The Reading Matrix 5(2), viewed 10 November 2016, from http://www.readingmatrix.com/articles/powell/ article.pdf

Pretorius, E.J., 2000, Inference generation in the reading of expository texts by university students, Unpublished doctoral thesis, University of South Africa, university
Pretoria.

Pretorius, E.J. \& Lephalala, M., 2011, 'Reading comprehension in high-poverty schools: How should it be taught and how well does it work?', Per Linguam 27(2), 1-24. https://doi.org/10.1111/j.1467-9817.2006.00333.x

Pretorius, E.J. \& Mampuru, D.M., 2007, 'Playing football without a ball: Language, reading and academic performance in a high poverty school', Journal of Reading Research 30(1), 38-58.

Rodrigo, V., Greenberg, D., Burke, V., Hall, R., Berry, A., Brinck, T. et al., 2007, 'Implementing an ER program and library for adult literacy learners', Reading in a Foreign Language 19(2), 106-119.

Savas, B., 2009, 'Role of functional academic literacy in ESP teaching: ESP teacher training in Turkey for sustainable development', The Journal of International Socia Research 2(9), 395-406.

Safaeia, L.A. \& Bulca, M., 2013, 'ER and creative practices', viewed 10 July 2016, from http://www.sciencedirect.com/science/article/pii/S1877042813000980\#

Scott, L. \& Saaiman, E., 2016, 'Promoting reading skills or wasting time? Students' perceived benefits of reading in an intermediary programme at the Vaal University of Technology', Reading \& Writing 7(1), 1-11. https://doi.org/10.4102/rw.v7i1.82

Sun, Y.C., 2003, 'ER online: An overview and evaluation', Journal of Computer Assisted Learning 19(4), 438-446. https://doi.org/10.1046/j.0266-4909.2003.00048

Van Staden, S. \& Howie, S., 2010, 'South African teacher profiles and emerging teacher factors: The picture painted by PIRLS 2006', Reading \& Writing 1(1), 47-60. https://doi.org/10.4102/rw.v1i1.4

Warring, R. \& Takaki, M., 2003, 'At what rate do learners learn and retain new vocabulary from reading a graded reader?', Reading in a Foreign Language 15(2), 130-163.

Yamashita, J., 2004, 'Reading attitudes in L1 and L2, and their influence on L2 ER', Reading in a Foreign Language 16(1), viewed 18 July 2016, from http://nflrc. hawaii.edu/rfl/April2004/yamashita/yamashita.html

Yamashita, J., 2008, 'ER and development of different aspects of L2 proficiency', System 36, 661-672. https://doi.org/10.1016/j.system.2008.04.003

Yeld, N., 2009, 'The National Benchmark Tests Project: Addressing student educational needs in the tertiary education system', Transformation Audit 2009, 73-83.

Zimmerman, L. \& Long, C., 2008, 'Teachers and reading instruction', in S. Howie, E. Venter, S. van Staden, L. Zimmerman, C. Long, C. du Toit, et al. (eds.), PIRLS 2006 summary report: South African children's reading literacy achievement, pp. 45-49, University of Pretoria, Pretoria. 